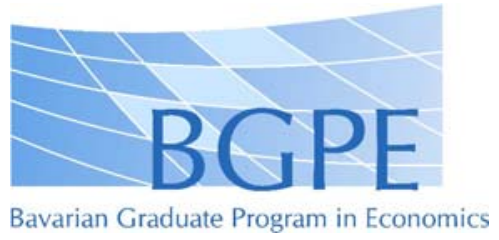

BGPE Discussion Paper

No. 21

\title{
Optimal Simple Rules for Fiscal Policy in a Monetary Union
}

\author{
Lukas Vogel \\ Werner Roeger \\ Bernhard Herz
}

December 2006

ISSN 1863-5733

Editor: Prof. Regina T. Riphahn, Ph.D.

Friedrich-Alexander-University Erlangen-Nuremberg

(c) Lukas Vogel, Werner Roeger, Bernhard Herz 


\title{
Optimal Simple Rules for Fiscal Policy in a Monetary Union
}

Lukas Vogel

Bayreuth University
Werner Roeger

European Commission
Bernhard Herz ${ }^{*}$

Bayreuth University

\section{December 2006}

\begin{abstract}
The paper discusses the stabilizing potential of fiscal policy in a dynamic general-equilibrium model of monetary union. We consider a small open economy inside the currency area. We analyze the demand and supply effects of direct taxation, indirect taxation and government spending and derive optimal simple rules for fiscal stabilization of a technology shock. Fiscal policy achieves substantial macroeconomic stabilization. Simple public-expenditure rules show the highest degree of both output and inflation stabilization. The implementation lag substantially weakens output stabilization, but hardly affects the stabilization of prices. Output-oriented rules imply less instrument inertia than inflation-dominated rules. The implementation lag leads to higher coefficients for inflation relative to output in the optimal rule. Compared to the single-instrument approach the simultaneous optimization of two instrument rules implies only little additional stabilization gains.
\end{abstract}

JEL classification: E 37, E 62, F 41

Keywords: Fiscal policy, monetary union, simple policy rules

\footnotetext{
* Corresponding author: Bayreuth University, D-95440 Bayreuth, Germany, email: bernhard.herz@uni-bayreuth,
} phone: +49-921-552912, fax: +49-921552949 


\section{Introduction}

This paper investigates the potential of fiscal policy to stabilize output and inflation. We consider a small country inside a monetary union and model the dynamics of output and inflation in an inter-temporal optimization framework. We assume perfect capital and goods market integration inside the union, i.e. an integrated capital market with perfect risk sharing and a lack of trade barriers. This setting implies that the law of one price holds inside the monetary union. To keep the model simple and to focus our analysis we disregard financial and trade linkages between the monetary union and the rest of the world.

The model combines inter-temporally optimizing behavior of households and firms with nominal rigidities. We assume infinitely-lived Ricardian households and the absence of liquidity constraints. The deficit approach regards fiscal policy as rather impotent in this case, as it does not imply strong income effects of taxation. Fiscal instruments have strong substitution effects in this environment, however, which affect the behavior of inter-temporally optimizing agents and the supply and demand side of the economy.

In previous work (vgl. Herz et al. 2005), we have considered a small open economy under fixed exchange rates, but without a monetary policy that actively stabilizes the macro dynamics of the rest of the world, or the union aggregate. In this case, equilibrium uniqueness in the small economy requires active fiscal stabilization. This paper modifies the approach and focuses on the situation, where monetary policy stabilizes the currency union aggregate. Fiscal policy is not required for equilibrium uniqueness in this case. But it remains a successful tool to reduce cyclical fluctuations and to dampen the impact of asymmetric shocks, or the asymmetric transmission of union-wide disturbances at the national level.

We build our analysis on the Galí/ Monacelli (2005) model of monetary and fiscal policy in monetary union and extend the framework in four directions. We adopt a more gen- 
eral specification of utility, and we increase the number of fiscal instruments. Instead of limiting the discussion to government consumption as in Galí/ Monacelli (2005) we also investigate the demand- and supply-side effects of direct and indirect taxation and their stabilizing potential. Thirdly, we investigate the impact of an implementation lag on the stabilizing performance of fiscal policy. Fourthly, we consider the combination of fiscal instruments and simultaneously optimal instrument rules.

\section{Model}

This section illustrates the impact of fiscal policy on the optimizing behavior of households and firms. We examine the demand and supply side effects of distortionary taxation and of government consumption in a small open economy. We build our discussion on the small open economy framework for monetary policy analysis developed in Galí/ Monacelli (2002) and on the Galí/ Monacelli (2005) model of monetary union. Looking at a monetary union allows us to disregard nominal exchange rates and their impact on the terms of trade. Stabilizing the aggregate monetary policy furthermore anchors the output and inflation dynamics of the small country inside the union. There is no feedback from the small economy to monetary union, on the other hand. The impact of the small country on the aggregate variables and on monetary policy is assumed to be negligible.

\subsection{Private households}

The representative household has infinite lifetime. Its overall utility equals the discounted sum of period utility

(1) $\quad U=E_{t} \sum_{i=0}^{\infty} \beta^{i} U_{t+i}$, 
with $\beta$ as the discount factor. Utility is additive in consumption and leisure. We assume

$$
U_{t}\left(C_{t}, N_{t}\right)=\frac{1}{1-\sigma} C_{t}^{1-\sigma}+F\left(G_{t}\right)-\frac{\vartheta}{1+\varphi} N_{t}^{1+\varphi}
$$

where $C$ is consumption, $F\left(G_{t}\right)$ is the utility derived from government consumption, and $N$ measures working time. The parameter $\vartheta$ quantifies the relative weight of foregone leisure, $\sigma^{-1}$ the inter-temporal elasticity of substitution and $\varphi^{-1}$ the elasticity of labor supply. We assume monopolistic competition in goods markets and a competitive labor market. Overall consumption utility is a CES function of domestic $\left(C_{H}\right)$ and foreign commodities $\left(C_{F}\right)$

(3) $C_{t}=\left[(1-\alpha)^{\frac{1}{\eta}} C_{H, t} \frac{\eta-1}{\eta}+\alpha^{\frac{1}{\eta}} C_{F, t}^{\frac{\eta-1}{\eta}}\right]^{\frac{\eta}{\eta-1}}$,

where $\eta$ quantifies the elasticity of substitution between imports and domestic commodities. The optimal consumption plan implies

(4a) $\quad C_{H, t}=(1-\alpha)\left(P_{H, t} P_{t}^{-1}\right)^{-\eta} C_{t}$ and $\quad C_{F, t}=\alpha\left(P_{F, t} P_{t}^{-1}\right)^{-\eta} C_{t}$

It gives the approximated log-linear demand functions

$$
\hat{c}_{H, t}=-\eta\left(\hat{p}_{H, t}-\hat{p}_{t}\right)+\hat{c}_{t} \quad \hat{c}_{F, t}=-\eta\left(\hat{p}_{F, t}-\hat{p}_{t}\right)+\hat{c}_{t},
$$

where $\hat{x}_{t} \equiv \ln X_{t}-\ln \bar{X}$ indicates the percentage deviation of a variable $X_{t}$ from its steady state value $\bar{X}$. Inserting the equations (4) in (3) gives

$$
P_{t}=\left([1-\alpha] P_{H, t}{ }^{1-\eta}+\alpha P_{F, t}^{1-\eta}\right)^{\frac{1}{1-\eta}}
$$

as the price level of domestic household consumption. The log-linear approximation around 
the steady state reads

$$
\hat{p}_{t}=(1-\alpha) \hat{p}_{H, t}+\alpha \hat{p}_{F, t} .
$$

When $P_{H, t}=P_{F, t}$, the share of imports in domestic consumption equals $\alpha$. The latter thus indicates the country’s openness to trade in the steady state. Domestic and imported goods are both bundles of differentiated products

$$
C_{H, t}=\left(\int_{0}^{1} C_{h, t} \frac{\varepsilon-1}{\varepsilon} d h\right)^{\frac{\varepsilon}{\varepsilon-1}} \quad C_{F, t}=\left(\int_{0}^{1} C_{f, t} \frac{\varepsilon-1}{\varepsilon} d f\right)^{\frac{\varepsilon}{\varepsilon-1}},
$$

with $\varepsilon$ as the elasticity of substitution between varieties in each bundle.

We assume full access of private households to asset markets and perfect risk diversification. The flow budget constraint of the representative household equals

(7a) $\quad\left(1-\tau_{t}^{w}\right) W_{t} N_{t}+D_{t}+T_{t}=\left(1+\tau_{t}^{c}\right) P_{t} C_{t}+B_{t+1}-\left(1+i_{t}\right) B_{t}$.

$W_{t}$ is the nominal wage per unit of labor and $\tau^{w}$ the tax on labor income. $D_{t}$ nominal profits from firm ownership, whereas $T_{t}$ are net lump-sum transfers from the government to the private households. The nominal expenditure on consumption equals $\left(1+\tau_{t}^{c}\right) P_{t} C_{t}$. It is composed of the expenditure for domestic goods $\left(1+\tau_{t}^{c}\right) P_{H, t} C_{H, t}$ and foreign commodities $\left(1+\tau_{t}^{c}\right) P_{F, t} C_{F, t}$. The expression $B_{t+1}-\left(1+i_{t}\right) B_{t}$ gives the investment in one-period bonds in period t, with $B \equiv B_{H}+B_{F}$ as a composite of risk-free domestic and foreign assets. To simplify the model we do not include physical capital as a factor of production.

An equivalent budget restriction holds for the foreign households. Designating foreign country variables, i.e. the union aggregate, by an asterisk we obtain 
The representative household maximizes utility (1) and (2) under the budget constraints (7a) and (7b) respectively. The intertemporal optimality conditions for consumption read

(8a) $1=\beta\left(1+i_{t}\right) E_{t}\left[\left(\frac{C_{t+1}}{C_{t}}\right)^{-\sigma} \frac{1+\tau_{t}^{c}}{1+\tau_{t+1}^{c}} \frac{P_{t}}{P_{t+1}}\right] \quad$ and

(8b) $1=\beta\left(1+i_{t}^{*}\right) E_{t}\left[\left(\frac{C_{t+1}^{*}}{C_{t}^{*}}\right)^{-\sigma} \frac{\left(1+\tau_{t}^{c^{*}}\right) P_{t}^{*}}{\left(1+\tau_{t+1}^{c *}\right) P_{t+1}^{*}}\right]$,

where we assume behavioral similarity between domestic and foreign households in the sense that $\beta=\beta^{*}$ and $\sigma=\sigma^{*}$.

With $\beta=(1+\bar{r})^{-1}$ and $\ln \left(1+\tau_{t}^{c}\right)-\ln \left(1+\bar{\tau}^{c}\right) \approx \frac{\bar{\tau}^{c}}{1+\bar{\tau}^{c}} \hat{\tau}_{t}^{c}$ we obtain the Euler equations

(9a) $\hat{c}_{t}=E_{t} \hat{c}_{t+1}-\frac{1}{\sigma}\left(i_{t}-\frac{\bar{\tau}^{c}}{1+\bar{\tau}^{c}} E_{t} \Delta \hat{\tau}_{t+1}^{c}-E_{t} \hat{\pi}_{t+1}-\bar{r}\right) \quad$ and

(9b) $\hat{c}_{t}^{*}=E_{t} \hat{c}_{t+1}^{*}-\frac{1}{\sigma}\left(i_{t}^{*}-\frac{\bar{\tau}^{c^{*}}}{1+\bar{\tau}^{c^{*}}} E_{t} \Delta \hat{\tau}_{t+1}^{c^{*}}-E_{t} \hat{\pi}_{t+1}^{*}-\bar{r}^{*}\right)$

for private household consumption around the steady state.

The optimal domestic and foreign labor supplies in competitive labor markets are

(10a) $\quad \hat{w}_{t}-\frac{\bar{\tau}^{w}}{1-\bar{\tau}^{w}} \hat{\tau}_{t}^{w}-\frac{\bar{\tau}^{c}}{1+\bar{\tau}^{c}} \hat{\tau}_{t}^{c}-\hat{p}_{t}=\varphi \hat{n}_{t}+\sigma \hat{c}_{t}+\hat{\vartheta}_{t}$

(10b) $\quad \hat{w}_{t}^{*}-\frac{\bar{\tau}^{w^{*}}}{1-\bar{\tau}^{w^{*}}} \hat{\tau}_{t}^{w^{*}}-\frac{\bar{\tau}^{c^{*}}}{1+\bar{\tau}^{c^{*}}} \hat{\tau}_{t}^{c^{*}}-\hat{p}_{t}^{*}=\varphi \hat{n}_{t}^{*}+\sigma \hat{c}_{t}^{*}+\hat{\vartheta}_{t}^{*}$ 
The equations (10) indicate that increases in the tax rate on income and consumption reduce the real wage and the labor supply.

The integrated capital market with a common monetary policy implies $i_{t}=i_{t}^{*}$. Equating the optimality condition (8a) and (8b) gives us

$C_{t}=E_{t}\left[\left(\frac{1+\tau_{t+1}^{c}}{1+\tau_{t+1}^{c^{*}}} \frac{P_{t+1}}{P_{t+1}^{*}}\right)^{\frac{1}{\sigma}} \frac{C_{t+1}}{C_{t+1}^{*}}\right]\left(\frac{1+\tau_{t}^{c^{*}}}{1+\tau_{t}^{c}}\right)^{\frac{1}{\sigma}}\left(\frac{P_{t}^{*}}{P_{t}}\right)^{\frac{1}{\sigma}} C_{t}^{*}$

The expression $E_{t}\left[\left(\frac{1+\tau_{t+1}^{c}}{1+\tau_{t+1}^{c^{*}}} \frac{P_{t+1}}{P_{t+1}^{*}}\right)^{\frac{1}{\sigma}} \frac{C_{t+1}}{C_{t+1}^{*}}\right]$ is constant in the steady state. Under symmetric initial conditions, i.e. with an equal initial endowment and steady-state consumption of domestic and foreign households, it is equal to one. Under perfect international risk sharing we thus obtain the log-linear relationship

$$
\hat{c}_{t}=\frac{1}{\sigma}\left(\hat{p}_{t}^{*}+\frac{\bar{\tau}^{c^{*}}}{1+\bar{\tau}^{c^{*}}} \hat{\tau}_{t}^{c^{*}}-\hat{p}_{t}-\frac{\bar{\tau}^{c}}{1+\bar{\tau}^{c}} \hat{\tau}_{t}^{c}\right)+\hat{c}_{t}^{*}
$$

between domestic and foreign household consumption. It indicates a negative relationship between relative prices and tax levels, on the one hand, and relative consumption levels, on the other hand. The higher domestic consumer prices are compared to the rest of the union, the lower is private domestic consumption relative to the union average.

\subsection{Government sector}

The government taxes labor and consumption, pays lump-sum transfers and purchases commodities. In addition to distortionary and lump-sum taxation the government can issue oneperiod bonds to finance public expenditure to balance its budget. In nominal terms the gov- 
ernment budget constraint reads

$$
P_{H, t} G_{t}+T_{t}=\tau_{t}^{w} W_{t} N_{t}+\tau_{t}^{c} P_{t} C_{t}+B_{H, t+1}-\left(1+i_{t}\right) B_{H, t} .
$$

We impose $\lim _{t \rightarrow \infty} R_{t} B_{H, t+1}=0$ with $R_{t} \equiv \prod_{n=1}^{t} \frac{1}{1+i_{n}}$ as transversality condition. This condition implies that the government cannot run Ponzi schemes and private households do not waste part of their wealth. All public debt must eventually be repaid.

With regard to public demand we assume that all government consumption $G_{t}$ goes to domestic production, and that it is based on a CES utility function $G_{t}=\left(\int_{0}^{1} G_{h, t}^{\frac{\varepsilon-1}{\varepsilon}} d h\right)^{\frac{\varepsilon}{\varepsilon-1}}$, so that the optimal allocation of public demand on each variety $h$ equals $G_{h, t}=\left(P_{h, t} P_{H, t}^{-1}\right)^{-\varepsilon} G_{t}$.

An equivalent budget constraint and an equivalent transversality condition hold for the monetary union aggregate. Again we assume that public demand is entirely devoted to home country production, i.e. that governments do not consume imported goods. The assumption implies that foreign private consumption is the only source of export demand.

\subsection{The monetary union}

In order to keep the model simple we assume that the monetary union consists of open economies, but that it is closed vis-à-vis the rest of the world. The small open member economy has no notable impact on the union aggregate. There is thus no feedback from the small country to the union, neither with regard to exogenous shocks nor with regard to policy. Aggregate demand in the union thus amounts to $Y_{t}^{*}=C_{t}^{*}+G_{t}^{*}$. With $\gamma \equiv \frac{\bar{G}}{\bar{Y}}$ as the steady state share of public demand in total output we obtain the log-linear demand equation 


$$
\hat{y}_{t}^{*}=(1-\gamma) \hat{c}_{t}^{*}+\gamma \hat{g}_{t}^{*}
$$

Replacing $c_{t}^{*}$ by equation (10b) and, subsequently, $E_{t} c_{t+1}^{*}$ by the expected value from equation (13) gives us

$$
\hat{y}_{t}^{*}=E_{t} \hat{y}_{t+1}^{*}-\frac{1-\gamma}{\sigma}\left(i_{t}^{*}-\frac{\bar{\tau}^{c^{*}}}{1+\bar{\tau}^{c^{*}}} E_{t} \Delta \hat{\tau}_{t+1}^{c^{*}}-E_{t} \pi_{t+1}^{*}-\bar{r}^{*}\right)-\gamma E_{t} \Delta \hat{g}_{t+1}^{*}
$$

as the inter-temporal aggregate demand equation for the monetary union.

To simplify the supply side of the model, we assume that firms produce output with constant returns to scale and labor as the only factor of production. Each firm produces a variety according to $Y_{f, t}=A_{t} N_{f, t}$ and $Y_{h, t}=A_{t} N_{h, t}$ respectively. The aggregate production function can be approximated at first order as $\hat{y}_{t}=\hat{a}_{t}+\hat{n}_{t} \cdot{ }^{1}$ The combination of monopolistic competition in goods market and staggered forward-looking price setting (see Calvo 1983) gives us the New Keynesian Phillips curve

$$
\hat{\pi}_{t}^{*}=\beta E_{t} \hat{\pi}_{t+1}^{*}+\lambda \hat{m} c_{t}^{*}
$$

with $\lambda \equiv(1-\theta)(1-\beta \theta) \theta^{-1}$, describing the dynamics of goods prices, net of taxes, around the steady state. The parameter $1-\theta$ quantifies the share of firms resetting prices in period $t$.

The log deviation of real marginal costs, $\hat{m} c_{t}^{*}$, can be replaced as $\hat{m} c_{t}^{*}=\hat{w}_{t}^{*}-\hat{p}_{t}^{*}-\hat{a}_{t}^{*}$. If we insert the labor supply equation (10b) and subsequently replace $\hat{n}_{t}^{*}$ by the production function $\hat{y}_{t}^{*}=\hat{a}_{t}^{*}+\hat{n}_{t}^{*}$ and $\hat{c}_{t}^{*}$ by equation (13) we obtain

\footnotetext{
${ }^{1}$ See Galí and Monacelli (2002) for the derivation of this result.
} 
(16) $\hat{m} c_{t}^{*}=\left(\varphi+\frac{\sigma}{1-\gamma}\right) \hat{y}_{t}^{*}-\frac{\gamma \sigma}{1-\gamma} \hat{g}_{t}^{*}+\frac{\bar{\tau}^{*}}{1+\bar{\tau}^{*}} \hat{\tau}_{t}^{c^{*}}+\frac{\bar{\tau}^{w^{*}}}{1-\bar{\tau}^{w^{*}}} \hat{\tau}_{t}^{w^{*}}-(1+\varphi) \hat{a}_{t}^{*}+\hat{\vartheta}_{t}^{*}$

as the marginal cost equation for the monetary union aggregate around its steady state. 


\subsection{The small economy in monetary union}

The small economy has no impact on the union aggregate dynamics of output and inflation. But aggregate variables affect the small member country. Total demand for domestically produced goods is the sum of domestic household demand for domestically produced goods, domestic public demand and export demand

$$
Y_{t}=C_{H, t}+C_{H, t}^{*}+G_{t}
$$

Log-linearizing the output equation (17) around the steady state gives us

$$
\hat{y}_{t}=(1-\alpha)(1-\gamma) \hat{c}_{H, t}+\alpha(1-\gamma) \hat{c}_{H, t}^{*}+\gamma \hat{g}_{t} .
$$

We can now insert the demand function (4b) as well as the equivalent function for export demand, $\hat{c}_{H, t}^{*}=-\eta\left(\hat{p}_{H, t}-\hat{p}_{t}^{*}\right)+\hat{c}_{t}^{*}$. Together with equation (5) and $p_{F, t}=p_{t}^{*}$, which assumes the absence of transport costs and price discrimination, we obtain

$$
\hat{y}_{t}=(1-\alpha)(1-\gamma) \hat{c}_{t}+\alpha(1-\gamma) \hat{c}_{t}^{*}+(2-\alpha) \alpha \eta(1-\gamma)\left(\hat{p}_{t}^{*}-\hat{p}_{H, t}\right)+\gamma \hat{g}_{t} .
$$

Finally, we use equation (11) derived from perfect risk sharing to replace domestic household consumption, $\hat{c}_{t}$. This gives us

$$
\hat{y}_{t}=(1-\gamma) \hat{c}_{t}^{*}+\gamma \hat{g}_{t}+(1-\gamma) \frac{\omega_{a}}{\sigma}\left(\hat{p}_{t}^{*}-\hat{p}_{H, t}\right)+(1-\gamma) \frac{1-\alpha}{\sigma}\left(\frac{\bar{\tau}^{c^{*}}}{1+\bar{\tau}^{c^{*}}} \hat{\tau}_{t}^{c^{*}}-\frac{\bar{\tau}^{c}}{1+\bar{\tau}^{c}} \hat{\tau}_{t}^{c}\right),
$$

with $\omega_{\alpha} \equiv 1+(2-\alpha) \alpha(\eta \sigma-1)$, for aggregate demand in the small open economy inside monetary union. Replacing $\hat{c}_{t}^{*}$ by equation (13) and assuming the steady state share of public spending to GDP to be identical in the small country and the union aggregate we obtain 


$$
\hat{y}_{t}=\hat{y}_{t}^{*}+\gamma\left(\hat{g}_{t}-\hat{g}_{t}^{*}\right)+(1-\gamma) \frac{\omega_{a}}{\sigma}\left(\hat{p}_{t}^{*}-\hat{p}_{H, t}\right)+(1-\gamma) \frac{1-\alpha}{\sigma}\left(\frac{\bar{\tau}^{c^{*}}}{1+\bar{\tau}^{c^{*}}} \hat{\tau}_{t}^{c^{*}}-\frac{\bar{\tau}^{c}}{1+\bar{\tau}^{c}} \hat{\tau}_{t}^{c}\right)
$$

The supply side combines monopolistic competition with staggered price setting in the goods market, and a competitive labor market. Inflation thus follows a New Keynesian Phillips curve analogous to equation (15) for the monetary union block. We have

$$
\hat{\pi}_{H, t}=\beta E_{t} \hat{\pi}_{H, t+1}+\lambda \hat{m} c_{t}
$$

for domestic goods prices net of consumption taxes. Real marginal costs are affected by labor supply and technology. Inserting equations (5) and (10a) and replacing $\hat{n}_{t}$ by the production function $\hat{y}_{t}=\hat{a}_{t}+\hat{n}_{t}$ gives

$$
\hat{m} c_{t}=\varphi \hat{y}_{t}+\sigma \hat{\tau}_{t}+\frac{\bar{\tau}^{c}}{1+\bar{\tau}^{c}} \hat{\tau}_{t}^{c}+\frac{\bar{\tau}^{w}}{1-\bar{\tau}^{w}} \hat{\tau}_{t}^{w}+\alpha\left(\hat{p}_{t}^{*}-\hat{p}_{H, t}\right)-(1+\varphi) \hat{a}_{t}+\hat{\vartheta}_{t} .
$$

In two further steps we first substitute $\hat{c}_{t}$ by equation (11) and then replace the terms of trade, $\hat{p}_{t}^{*}-\hat{p}_{H, t}$, by the aggregate demand equation (19) to obtain marginal costs as

$$
\begin{aligned}
\hat{m} c_{t} & =\left(\varphi+\frac{1}{1-\gamma} \frac{\sigma}{\omega_{\alpha}}\right) \hat{y}_{t}-\frac{\gamma}{1-\gamma} \frac{\sigma}{\omega_{\alpha}} \hat{g}_{t}+\frac{\bar{\tau}^{w}}{1-\bar{\tau}^{w}} \hat{\tau}_{t}^{w}+\frac{1-\alpha}{\omega_{\alpha}} \frac{\bar{\tau}^{c}}{1+\bar{\tau}^{c}} \hat{\tau}_{t}^{c}+\left(1-\frac{1}{\omega_{\alpha}}\right) \sigma \hat{c}_{t}^{*}, \text { which } \\
& +\left(1-\frac{1-\alpha}{\omega_{\alpha}}\right) \frac{\bar{\tau}^{c^{*}}}{1+\bar{\tau}^{c^{*}}} \hat{\tau}_{t}^{c^{*}}-(1+\varphi) \hat{a}_{t}+\hat{\vartheta}_{t}
\end{aligned}
$$

equals the marginal costs equation in Herz et al. (2005). Without income and consumption taxes and assuming $\eta=\sigma=1$ the expression simplifies to

$$
\hat{m} c_{t}=\left(\varphi+\frac{1}{1-\gamma}\right) \hat{y}_{t}-\frac{\gamma}{1-\gamma} \hat{g}_{t}-(1+\varphi) \hat{a}_{t}+\hat{\vartheta}_{t},
$$

which is the marginal cost equation for the small open economy in Galí/ Monacelli (2005). 
Finally we can replace foreign household consumption, $\hat{c}_{t}^{*}$, by the union's resource constraint (13). This gives us marginal costs in the small country as

$$
\begin{aligned}
\hat{m} c_{t} & =\left(\varphi+\frac{1}{1-\gamma} \frac{\sigma}{\omega_{\alpha}}\right) \hat{y}_{t}-\frac{\gamma}{1-\gamma} \frac{\sigma}{\omega_{\alpha}} \hat{g}_{t}+\frac{\bar{\tau}^{w}}{1-\bar{\tau}^{w}} \hat{\tau}_{t}^{w}+\frac{1-\alpha}{\omega_{\alpha}} \frac{\bar{\tau}^{c}}{1+\bar{\tau}^{c}} \hat{\tau}_{t}^{c}+\left(1-\frac{1}{\omega_{\alpha}}\right) \frac{\sigma}{1-\gamma} \hat{y}_{t}^{*} . \\
& -\left(1-\frac{1}{\omega_{\alpha}}\right) \frac{\gamma \sigma}{1-\gamma} \hat{g}_{t}^{*}+\left(1-\frac{1-\alpha}{\omega_{\alpha}}\right) \frac{\bar{\tau}^{c^{*}}}{1+\bar{\tau}^{c^{*}}} \hat{\tau}_{t}^{c^{*}}-(1+\varphi) \hat{a}_{t}+\hat{\vartheta}_{t}
\end{aligned}
$$

The marginal cost equation (22) is identical to the marginal cost equation for the small open economy in Herz et al. (2005).

\section{The monetary union aggregate:}

$$
\begin{aligned}
& \hat{y}_{t}^{*}=E_{t} y_{t+1}^{*}-\frac{1-\gamma}{\sigma}\left(i_{t}^{*}-\frac{\bar{\tau}^{c^{*}}}{1+\bar{\tau}^{c^{*}}} E_{t} \Delta \hat{\tau}_{t+1}^{c^{*}}-E_{t} \pi_{t+1}^{*}-\bar{r}^{*}\right)-\gamma E_{t} \Delta \hat{g}_{t+1}^{*} \\
& \hat{y}_{t}^{*}=(1-\gamma) \hat{c}_{t}^{*}+\gamma \hat{g}_{t}^{*} \\
& \pi_{t}^{*}=\beta E_{t} \pi_{t+1}^{*}+\lambda\left(\varphi+\frac{\sigma}{1-\gamma}\right) \hat{y}_{t}^{*}-\frac{\lambda \gamma \sigma}{1-\gamma} \hat{g}_{t}^{*}+\frac{\lambda \bar{\tau}^{c^{*}}}{1+\bar{\tau}^{c^{*}}} \hat{\tau}_{t}^{c^{*}}+\frac{\lambda \bar{\tau}^{w^{*}}}{1-\bar{\tau}^{w^{*}}} \hat{\tau}_{t}^{w^{*}}-\lambda(1+\varphi) \hat{a}_{t}+\lambda \hat{\vartheta}
\end{aligned}
$$

\section{The small economy:}

$$
\begin{aligned}
\hat{y}_{t}= & \hat{y}_{t}^{*}+\gamma\left(\hat{g}_{t}-\hat{g}_{t}^{*}\right)+(1-\gamma) \frac{\omega_{a}}{\sigma}\left(\hat{p}_{t}^{*}-\hat{p}_{H, t}\right)+(1-\gamma) \frac{1-\alpha}{\sigma}\left(\frac{\bar{\tau}^{c^{*}}}{1+\bar{\tau}^{c^{*}}} \hat{\tau}_{t}^{c^{*}}-\frac{\bar{\tau}^{c}}{1+\bar{\tau}^{c}} \hat{\tau}_{t}^{c}\right) \\
\pi_{H, t}= & \beta E_{t} \pi_{H, t+1}+\lambda\left(\varphi+\frac{1}{1-\gamma} \frac{\sigma}{\omega_{\alpha}}\right) \hat{y}_{t}-\frac{\lambda \gamma}{1-\gamma} \frac{\sigma}{\omega_{\alpha}} \hat{g}_{t}+\frac{\lambda \bar{\tau}^{w}}{1-\bar{\tau}^{w}} \hat{\tau}_{t}^{w}+\frac{1-\alpha}{\omega_{\alpha}} \frac{\lambda \bar{\tau}^{c}}{1+\bar{\tau}^{c}} \hat{\tau}_{t}^{c}-\lambda(1+\varphi) \hat{a}_{t} \\
& +\lambda \hat{\vartheta}_{t}+\left(1-\frac{1}{\omega_{\alpha}}\right) \frac{\lambda \sigma}{1-\gamma} \hat{y}_{t}^{*}-\left(1-\frac{1}{\omega_{\alpha}}\right) \frac{\lambda \gamma \sigma}{1-\gamma} \hat{g}_{t}^{*}+\left(1-\frac{1-\alpha}{\omega_{\alpha}}\right) \frac{\lambda \bar{\tau}^{c^{*}}}{1+\bar{\tau}^{c^{*}}} \hat{\tau}_{t}^{c^{*}}
\end{aligned}
$$

Table 1: The model in deviations from the steady state

Equation (22) illustrates the impact of taxation and government spending on marginal costs 
and aggregate supply. Both income and consumption taxes lower the real wage. They thus increase marginal production costs, as indicated by the positive sign in (22), and reduce labor supply. An increase in government spending reduces private wealth and lifetime private consumption. As consumption decreases the marginal utility of consumption relative to leisure increases. Consequently, private households increase their labor supply. The increase in labor supply lowers the marginal production costs, which is indicated by the negative sign on government consumption in equation (22).

\subsection{Output under flexible prices and the output gap}

The output gap $\tilde{y}_{t} \equiv \hat{y}_{t}-\hat{y}_{t}^{f}$ indicates the percentage deviation of output from its natural level, i.e. from the equilibrium level in the absence of nominal rigidities and conditional on foreign demand. Each firm adjusts prices in every period and charges a constant mark-up under perfectly flexible prices. Additionally we assume that the flexible-price equilibrium also coincides with the economy’s efficient level of production. Monopolistic competition leads to an inefficiently low level of production. We therefore assume that the government pays an employment subsidy to firms in order to offset the distortionary markup effect on output. If the employment subsidy offsets the markup distortion, the flexible-price equilibrium equals the efficient level of output. Closing the output gap then also achieves the efficient level of production (see e.g. Galí and Monacelli 2002, Woodford 2003).

Under flexible prices real marginal costs do not deviate from their steady-state level, i.e. $m \hat{c}_{t}^{f}=0$. For the deviation of real marginal costs from the flexible-price level we thus obtain $m \tilde{c}_{t} \equiv m \hat{c}_{t}-m \hat{c}_{t}^{f}=m \hat{c}_{t}-0=m \hat{c}_{t}$. We can therefore determine the fluctuation of potential output around the steady state, $\hat{y}_{t}^{f}$, by solving equation (22) for $m \hat{c}_{t}^{f}=0$. This gives us 


$$
\begin{aligned}
\hat{y}_{t}^{f}= & \frac{\gamma}{1-\gamma} \sigma \Theta \hat{g}_{t}^{f}-(1-\alpha) \Theta \frac{\bar{\tau}^{c}}{1+\bar{\tau}^{c}} \hat{\tau}_{t}^{c f}-\omega_{\alpha} \Theta \frac{\bar{\tau}^{w}}{1-\bar{\tau}^{w}} \hat{\tau}_{t}^{w f}+(1+\varphi) \omega_{\alpha} \Theta \hat{a}_{t}^{f} \\
& -\omega_{\alpha} \Theta \hat{\vartheta}_{t}^{f}-\frac{\omega_{\alpha}-1}{1-\gamma} \sigma \Theta \hat{y}_{t}^{*}+\frac{\omega_{\alpha}-1}{1-\gamma} \gamma \sigma \Theta \hat{g}_{t}^{*}+\left(1-\alpha-\omega_{\alpha}\right) \Theta \frac{\bar{\tau}^{c^{*}}}{1+\bar{\tau}^{c^{*}}} \hat{\tau}_{t}^{c^{*}},
\end{aligned}
$$

with $\Theta \equiv \frac{1-\gamma}{(1-\gamma) \omega_{\alpha} \varphi+\sigma}$.

If we subtract the marginal costs under flexible prices from the actual deviation of marginal costs from the steady state $m \tilde{c}_{t} \equiv m \hat{c}_{t}-m \hat{c}_{t}^{f}=m \hat{c}_{t}-0=m \hat{c}_{t}$ and define $\tilde{\tau}_{t}^{c} \equiv \hat{\tau}_{t}^{c}-\hat{\tau}_{t}^{c f}$, $\tilde{\tau}_{t}^{w} \equiv \hat{\tau}_{t}^{w}-\hat{\tau}_{t}^{w f}$ and $\tilde{g}_{t} \equiv \hat{g}_{t}-\hat{g}_{t}^{f}$, we obtain

$$
\hat{m} c_{t}=\left(\varphi+\frac{1}{1-\gamma} \frac{\sigma}{\omega_{\alpha}}\right) \tilde{y}_{t}-\frac{\gamma}{1-\gamma} \frac{\sigma}{\omega_{\alpha}} \tilde{g}_{t}+\frac{\bar{\tau}^{w}}{1-\bar{\tau}^{w}} \tilde{\tau}_{t}^{w}+\frac{1-\alpha}{\omega_{\alpha}} \frac{\bar{\tau}^{c}}{1+\bar{\tau}^{c}} \tilde{\tau}_{t}^{c},
$$

where we assume $\hat{a}_{t}=\hat{a}_{t}^{f}, \hat{\vartheta}_{t}=\hat{\vartheta}_{t}^{f}$ and the exogeneity of foreign country variables. The New Keynesian Phillips curve now reads

$$
\pi_{H, t}=\beta E_{t} \pi_{H, t+1}+\lambda\left(\varphi+\frac{1}{1-\gamma} \frac{\sigma}{\omega_{\alpha}}\right) \tilde{y}_{t}-\frac{\lambda \gamma}{1-\gamma} \frac{\sigma}{\omega_{\alpha}} \tilde{g}_{t}+\frac{\lambda \bar{\tau}^{w}}{1-\bar{\tau}^{w}} \tilde{\tau}_{t}^{w}+\frac{1-\alpha}{\omega_{\alpha}} \frac{\lambda \bar{\tau}^{c}}{1+\bar{\tau}^{c}} \tilde{\tau}_{t}^{c}
$$

To relate aggregate demand to the output gap we subtract the output level under flexible prices in equation (23) from the actual output as given by equation (19). From this we get

$$
\begin{aligned}
\tilde{y}_{t}= & \gamma \hat{g}_{t}+(1-\gamma) \frac{\omega_{a}}{\sigma}\left(\hat{p}_{t}^{*}-\hat{p}_{H, t}\right)-(1-\gamma) \frac{1-\alpha}{\sigma} \frac{\bar{\tau}^{c}}{1+\bar{\tau}^{c}} \hat{\tau}_{t}^{c}-\frac{\gamma}{1-\gamma} \sigma \Theta \hat{g}_{t}^{f} \\
& +(1-\alpha) \Theta \frac{\bar{\tau}^{c}}{1+\bar{\tau}^{c}} \hat{\tau}_{t}^{c f}+\omega_{\alpha} \Theta \frac{\bar{\tau}^{w}}{1-\bar{\tau}^{w}} \hat{\tau}_{t}^{w f}-(1+\varphi) \omega_{\alpha} \Theta \hat{a}_{t}+\omega_{\alpha} \Theta \hat{\vartheta}_{t} \\
& +\left(1-\frac{1-\omega_{\alpha}}{1-\gamma} \sigma \Theta\right) \hat{y}_{t}^{*}-\gamma\left(1-\frac{1-\omega_{\alpha}}{1-\gamma} \sigma \Theta\right) \hat{g}_{t}^{*}+(1-\gamma)\left(\frac{1-\alpha}{\sigma}-\frac{1-\alpha-\omega_{\alpha}}{1-\gamma} \Theta\right) \frac{\bar{\tau}^{c^{*}}}{1+\bar{\tau}^{c^{*}}} \hat{\tau}_{t}^{c^{*}}
\end{aligned}
$$

If we assume that both taxes rates and public spending are kept at their steady-state levels as 
long as economic activity achieves its flexible-price equilibrium, we have $\hat{\tau}_{t}^{c f}=\hat{\tau}_{t}^{w f}=\hat{g}_{t}^{f}=0$. First differencing the previous equation gives us the change in the output gap as

$$
\Delta \tilde{y}_{t}=\gamma \Delta \tilde{g}_{t}-(1-\gamma) \frac{\omega_{a}}{\sigma} \pi_{H, t}-(1-\gamma) \frac{1-\alpha}{\sigma} \frac{\bar{\tau}^{c}}{1+\bar{\tau}^{c}} \Delta \tilde{\tau}_{t}^{c}+\Delta \varepsilon_{y, t},
$$

where

$$
\begin{aligned}
\varepsilon_{y, t} & \equiv-(1+\varphi) \omega_{\alpha} \Theta \hat{a}_{t}+\omega_{\alpha} \Theta \hat{\vartheta}_{t}+\left(1-\frac{1-\omega_{\alpha}}{1-\gamma} \sigma \Theta\right) \hat{y}_{t}^{*}-\gamma\left(1-\frac{1-\omega_{\alpha}}{1-\gamma} \sigma \Theta\right) \hat{g}_{t}^{*} \\
& +(1-\gamma)\left(\frac{1-\alpha}{\sigma}-\frac{1-\alpha-\omega_{\alpha}}{1-\gamma} \Theta\right) \frac{\bar{\tau}^{c^{*}}}{1+\bar{\tau}^{c^{*}}} \hat{\tau}_{t}^{c^{*}}+(1-\gamma) \frac{\omega_{a}}{\sigma} \hat{p}_{t}^{*}
\end{aligned}
$$

summarizes the exogenous disturbances to the output-gap equation.

The equations (25) and (27) describe the change of domestic goods prices net of taxes and the change of the output gap in the small open economy inside the monetary union. Fiscal policy affects both the supply and the demand side. As shown in equation (10), the supplyside effects result from the impact of fiscal policy on labor supply. Taxing consumption and labor income reduces the real wage, i.e. the opportunity cost of leisure. The resulting decline in the labor supply raises the marginal costs of production. An increase in public consumption, on the other hand, reduces private wealth. Given the decreasing marginal utility of consumption, the reduction of household wealth reduces real wages and marginal costs for a given level of production.

The demand effects of fiscal policy rest upon public expenditure and consumption taxes. Government expenditure is a component of aggregate demand itself. Changes in the consumption tax affect the behavior of optimizing households. A VAT reduction triggers an increase in private consumption, whereas a tax increase compresses private demand. The effect positively depends on the inter-temporal elasticity of substitution. The resulting impact 
on domestic output is furthermore a function of the share of domestic output in domestic private demand.

\subsection{Monetary and fiscal policy}

Monetary policy stabilizes output and inflation in the union as a whole. We assume that the central bank adjusts the nominal interest rate according to

$$
\hat{i}_{t}^{*}=\phi_{\pi}^{*} \hat{\pi}_{t}^{*}
$$

It thus follows a monetary policy rule, where nominal interest rates react to changes in aggregate inflation. Idiosyncratic shocks to the small open economy have no significant impact on the union aggregate. Therefore they do not affect monetary policy decisions.

Fiscal policy in the small economy attempts to dampen asymmetric business cyclical fluctuations. The optimal policy aims at minimizing the expected loss given by the function

$$
L=E_{t}\left[\sum_{i=0}^{\infty} \beta^{i}\left(q_{y} \tilde{y}_{t+i}^{2}+q_{\pi} \pi_{H, t+i}^{2}+q_{f} \Delta^{2} f_{t+i}\right)\right]
$$

with $\Delta f_{t}$ as the change in the fiscal instrument. The quadratic loss function can be derived as the quadratic approximation to household utility around the steady state. Woodford (2003) provides a detailed exposition for the closed economy. Galí and Monacelli (2002) derive the quadratic loss function for the small open economy case. Benigno and Woodford (2003) show that changes in distortionary taxation should not per se enter the welfare criterion. Many loss specifications for monetary policy do also include a positive weight on instrument changes, however (see Dieppe et al. 2005). The main motivation for including interest rate changes in the loss function is to reconcile the empirical finding of high interest rate smoothing with the assumption of optimizing monetary policy. The importance of credibility, model uncertainty 
and the destabilization of financial markets are theoretical arguments against frequent and strong interest rates changes. For fiscal policy $q_{f}>0$ may furthermore reflect political economy factors. Under the current institutional setting fiscal policy is more exposed to political pressures and to longer delays in reaction or implementation than monetary policy. ${ }^{2}$

The implementation lag of fiscal policy figures among the most prominent objections against the use of fiscal instruments for short-term macroeconomic stabilization. ${ }^{3}$ In contrast to previous work on fiscal stabilization (e.g., van Aarle et al. 2004, Beetsma and Jensen 2002, Galí and Monacelli 2004) we explicitly account for a delayed implementation of fiscal measures. We adopt the simple rule

$$
f_{t}=\phi_{y} \tilde{y}_{t-s}+\phi_{\pi} \pi_{H, t-s}+\phi_{f} f_{t-1}
$$

whereby $f_{t}$ designates the fiscal instrument. If $s=0$, fiscal policy reacts contemporaneously to output and inflation. If $s=1$, it reacts to macroeconomic fluctuations with a one-period delay. Comparing the results for $s=0$ and $s=1$ allows us to investigate whether a oneperiod delay in implementation weakens the stabilizing potential of fiscal policy in our model of inter-temporal optimizing households and firms.

Our analysis in chapter four focuses on optimal simple rules. Simple rules are easy to monitor and easy to understand. They reduce the government's incentive to deviate ex post from the ex ante optimal plan. If the announcement was lacking credibility, the reaction function would have little stabilizing effect on private-sector expectations. Giving an easy-to-

\footnotetext{
${ }^{2}$ To facilitate comparison among the different fiscal instruments we let $q_{f}$ refer to percentage-point changes of the respective instrument, as opposed to percentage changes relative to the steady state level. With $\Delta \hat{f}_{t} \equiv\left(f_{t}-f_{t-1}\right) \bar{f}^{-1}$ we can write the relationship between percentage-point and percentage changes as $\Delta f \equiv f_{t}-f_{t-1}=\Delta \hat{f}_{t} \bar{f}$.
} 
monitor reaction function simple rules thus attenuate the time-consistency problem attached to the implementation lag.

$$
\begin{aligned}
& \Delta \tilde{y}_{t}=\gamma \Delta \tilde{g}_{t}-(1-\gamma) \frac{\omega_{a}}{\sigma} \pi_{H, t}-(1-\gamma) \frac{1-\alpha}{\sigma} \frac{\bar{\tau}^{c}}{1+\bar{\tau}^{c}} \Delta \tilde{\tau}_{t}^{c}+\Delta \varepsilon_{y, t} \\
& \pi_{H, t}=\beta E_{t} \pi_{H, t+1}+\lambda\left(\varphi+\frac{1}{1-\gamma} \frac{\sigma}{\omega_{\alpha}}\right) \tilde{y}_{t}-\frac{\lambda \gamma}{1-\gamma} \frac{\sigma}{\omega_{\alpha}} \tilde{g}_{t}+\frac{\lambda \bar{\tau}^{w}}{1-\bar{\tau}^{w}} \tilde{\tau}_{t}^{w}+\frac{1-\alpha}{\omega_{\alpha}} \frac{\lambda \bar{\tau}^{c}}{1+\bar{\tau}^{c}} \tilde{\tau}_{t}^{c} \\
& f_{t}=\phi_{y} \tilde{y}_{t-s}+\phi_{\pi} \pi_{H, t-s}+\phi_{f} f_{t-1}
\end{aligned}
$$

Table 2: The output gap, inflation and fiscal policy in the small open economy

We summarize the small open economy model in table 2. The model consists of the output gap equation, the inflation equation and the fiscal rule. The output gap equation is conditional on foreign demand and changes in technology or household preferences. The New Keynesian Phillips curve is augmented by a cost push shock. As the economy is small, we do not have any feedback from the country dynamics to the monetary union aggregate.

\subsection{Stability analysis}

Inflation in the small open economy follows the New Keynesian Phillips curve in table 2. Its dynamic is forward looking. The output gap is backward looking, on the other hand. Stability and determinacy of the equilibrium thus requires one eigenvalue of the system to be smaller than one and one eigenvalue to be larger than one. Investigating the dynamics without policy intervention and neglecting the white-noise disturbance terms, we can rewrite the two equations as

\footnotetext{
${ }^{3}$ Other concerns relate to the insufficient reversibility of fiscal measures and to the long-run budgetary sustainability. Compared to monetary policy the fiscal impact lag appears to be rather short, however (see Blinder 2004).
} 
$\tilde{y}_{t}=\tilde{y}_{t-1}-a \pi_{H, t} \quad$ and

$\pi_{H, t}=\beta E_{t} \pi_{H, t+1}+b \tilde{y}_{t}$,

with $a \equiv(1-\gamma) \omega_{\alpha} \sigma^{-1}$ and $b \equiv \lambda\left(\varphi+\frac{1}{1-\gamma} \frac{\sigma}{\omega_{\alpha}}\right)$.

If we take first differences of the inflation equation and then insert the output equation we have $(1+\beta+a b) \pi_{H, t}-\beta E_{t} \pi_{H, t+1}-\pi_{H, t-1}=0$. Using the lag operator $L$ we write

$$
-\beta\left(1-\frac{1+\beta+a b}{\beta} L+\frac{1}{\beta} L^{2}\right) \pi_{H, t+2}=0 .
$$

Following the approach of Sargent (1987), we can factorize the expression in brackets into $\left(1-\delta_{1} L\right)\left(1-\delta_{2} L\right) \pi_{H, t+2}=0$, with $\delta_{1}+\delta_{2} \equiv(1+\beta+a b) \beta^{-1}$ and $\delta_{1} \delta_{2} \equiv \beta^{-1}$. Combining the last two expressions, we obtain $\beta \delta_{1}+\delta_{1}^{-1}=1+\beta+a b$. Because of $\delta_{1} \delta_{2} \equiv \beta^{-1}$ and the assumption on the time preference rate $0<\beta<1$ one of the eigenvalues has to be smaller then 1 and the other to be larger than one in modulus. The stability and determinacy requirements are thus fulfilled. This means that stability and determinacy of equilibrium does not require fiscal stabilization under efficient financial markets, i.e. perfect risk sharing, in a monetary union. Chapter four discusses the extent to which fiscal policy can smooth the adjustment to exogenous shocks. The scenario without stabilization policy provides a useful benchmark.

\section{Model calibration}

In section 2 we have developed the intertemporal-optimization model and discussed the qualitative impact of fiscal policy on aggregate demand and supply. We now calibrate the equations in table 1 in order to quantitatively assess the stabilizing performance of fiscal policy 
rules and to retrieve impulse responses to exogenous distortions. Table 2 summarizes the parameter values.

\begin{tabular}{|l|l|l|}
\hline Parameter & Symbol & Value \\
\hline Discount factor & $\beta$ & 0.99 \\
\hline Elasticity of labor supply & $\varphi^{-1}$ & 0.67 \\
\hline Elasticity of substitution between commodity bundles & $\eta$ & 1.00 \\
\hline Inter-temporal elasticity of substitution & $\sigma^{-1}$ & 1.00 \\
\hline Sensitivity of inflation to marginal costs & $\lambda$ & 0.09 \\
\hline Steady-state ratio of exports to GDP & $\alpha$ & 0.55 \\
\hline Steady-state ratio of public consumption to GDP & $\gamma$ & 0.27 \\
\hline Steady-state tax rate on consumption & $\bar{\tau}^{c}=\bar{\tau}^{c^{*}}$ & 0.20 \\
\hline Steady state tax rate on labor income & $\bar{\tau}^{w}=\bar{\tau}^{w^{*}}$ & 0.26 \\
\hline
\end{tabular}

Table 3: Model calibration

A time period corresponds to a quarter of a year. The (non-weighted) average shares of private and government consumption relative to GDP in the small EMU economies Austria, Belgium, Greece, Finland, Ireland, the Netherlands and Portugal are 0.55 and 0.20 respectively. As we do not separately account for investment expenditure, we scale these consumption shares to add up to one. The average ratio of exports to GDP for these countries is 0.55 (see European Commission 2003). The average income tax and VAT rates amount to 26\% and 20\% respectively (see OECD 2004). ${ }^{4}$ The remaining parameters values rely on standard choices. We set the inter-temporal elasticity of substitution to one, as in Clarida et al. (2000), the inverse of the labor supply elasticity to $\varphi=1.5$, as in Galí and Monacelli (2002). In accordance with Galí and Monacelli (2004) we also assume the elasticity of substitution be- 
tween domestic and foreign commodity bundles to equal one. The value $\theta=0.75$ for the probability of price non-adjustment implies an average contract length of one year and matches empirical observations (see Taylor, 1998). Together with $\beta=0.99$ we obtain $\lambda=0.086$, which is close to the EMU estimate of 0.09 in Galí et al. (2001). Table 4 displays the model equations under these parameter choices. We thereby consider the fiscal instruments in percentage-point deviations from their respective steady-state levels.

$$
\begin{aligned}
& \Delta \tilde{y}_{t}=\Delta(g-\bar{g})_{t}-0.73 \pi_{H, t}-0.27 \Delta\left(\tau^{c}-\bar{\tau}^{c}\right)_{t}+\Delta \varepsilon_{y, t} \\
& \pi_{H, t}=0.99 E_{t} \pi_{H, t+1}+0.26 \tilde{y}_{t}-0.12\left(g_{t}-\bar{g}\right)+0.12\left(\tau_{t}^{w}-\bar{\tau}^{w}\right)+0.03\left(\tau_{t}^{c}-\bar{\tau}^{c}\right) \\
& f_{t}=\phi_{y} \tilde{y}_{t-s}+\phi_{\pi} \pi_{H, t-s}+\phi_{f} f_{t-s}
\end{aligned}
$$

\section{Table 4: The calibrated model equations}

We consider the model dynamics in response to an autoregressive technology shock. We specify deviations of the technology parameter from its steady state as

$\hat{a}_{t}=\rho_{a} \hat{a}_{t-1}+\hat{\varepsilon}_{a, t}$

We assume an AR (1) parameter $\rho_{a}=0.82$ and 0.63 standard deviations for the innovation $\hat{\varepsilon}_{a, t}$. These values are in line with the euro-area estimates of Smeets and Wouters (2003). The output shock in equation (27) then becomes $\varepsilon_{y, t} \equiv-(1+\varphi) \omega_{\alpha} \Theta \hat{a}_{t}$. We treat the shock as an asymmetric disturbance that only hits the small economy, and we assume that the monetaryunion aggregate is in its steady state. There is no spill-over from the small country to the ag-

\footnotetext{
${ }^{4}$ We take the average VAT and labor income tax rate for the small EMU economies in 2003 to proxy the steady state level of indirect and direct taxation.
} 
gregate monetary union. We use DYNARE and its optimization tool (see Juillard 1996) to derive simple optimal instrument rules and to calculate the model's theoretical moments. ${ }^{5}$

\section{Simple optimal rules}

The optimal policy minimizes the loss function (29) given the equations (25) and (27). Its implementation faces two potential problems, however. Firstly, full optimization requires the policy maker to have perfect knowledge about the model structure. The second problem is the time consistency of optimal policy under delayed implementation. Simple policy rules can mitigate both problems (see Levin et al. 1999, Taylor 1999). They require less information about the economic environment, and they are less vulnerable to variations in economic structure ${ }^{6}$ Furthermore, simple rules are easy to understand and transparent. The commitment to a simple rule is thus easier to observe and to implement than the commitment to the fully optimal plan (see Beetsma and Jensen 2002, Dieppe et al. 2005). We focus our discussion on simple rules of the form (30). Fiscal policy reacts to the output gap and to inflation in domestic goods prices. For $s=0$ the reaction is contemporaneous, i.e. without implementation lag. For $s=1$ the rule implies a one-period delay in the reaction to macroeconomic fluctuations. Rule (30) furthermore allows for instrument smoothing.

Before we derive the optimal coefficients for the policy rule (30) we need to specify the relative weights in the loss function (29). We consider two different combinations of pa-

\footnotetext{
${ }^{5}$ The DYNARE routine is freely available and can be downloaded from http://www.cepremap.cnrs.fr/dynare.

${ }^{6}$ Taylor (1999) and Levine et al. (1999) illustrate in a monetary policy model that policies, which are optimal in a specific macroeconomic model, may perform poorly in a modified economic environment. Levine et al. (1999) conclude that "even in large models with hundreds of variables, three variables (the current output gap, the current four-quarter average inflation rate, and the lagged funds rate) summarize nearly all the information relevant to setting the federal funds rate efficiently”.
} 
rameters. The first scenario sets $q_{\pi}=1$ and $q_{y}=q_{f}=0.1$. This choice of coefficients corresponds to the high relative weight of inflation in the micro-funded loss function of New Keynesian models (see Galí and Monacelli 2005, Woodford 2003). For the discount factor $\beta$ converging to one the overall loss approximately amounts to

(31a) $L=0.1 \operatorname{var}(\tilde{y})+\operatorname{var}\left(\pi_{H}\right)+0.1 \operatorname{var}(\Delta f)$,

i.e. the weighted sum of the variances of the output gap, the domestic commodity-price inflation and the adjustment of the fiscal instrument.

Other research, as van Aarle et al. 2004, however argues from an empirical perspective that fiscal policy focuses more on output stabilization. ${ }^{7}$ The common central bank already stabilizes aggregate inflation and inflationary expectations at the union level. Therefore we also consider optimal simple rules for $q_{y}=1$ and $q_{\pi}=q_{f}=0.1$, which gives the loss function

$$
L=\operatorname{var}(\tilde{y})+0.1 \operatorname{var}\left(\pi_{H}\right)+0.1 \operatorname{var}(\Delta f)
$$

where the weight on the output gap is ten times higher than the weight on inflation. A comparison of the optimal rules for both loss specifications allows to investigate the robustness of simple optimal rules with respect to differences in policy objectives.

\footnotetext{
${ }^{7}$ For an empirical foundation of the loss function one could also consider rule estimates for the Euro area and search for the loss function that they fit best. Estimates of monetary reaction functions include Clarida et al. (1998), Gerdesmeier and Roffia (2004), Gerberding et al. (2004) and Muscatelli et al. (2004, 2004a). Dennis (2003), Favero and Rovelli (2002), Mayer (2003) and Söderström et al. (2002) provide empirically estimated loss functions for US monetary policy since the 1980s. Their results are very heterogeneous, and they strongly depend on the underlying methodology, however.
} 


\subsection{Optimal simple instrument rules}

This section presents numerical simulations for optimal simple policy rules under an autoregressive productivity shock. We compare the stabilization performance of the rules to the benchmark case without fiscal stabilization.
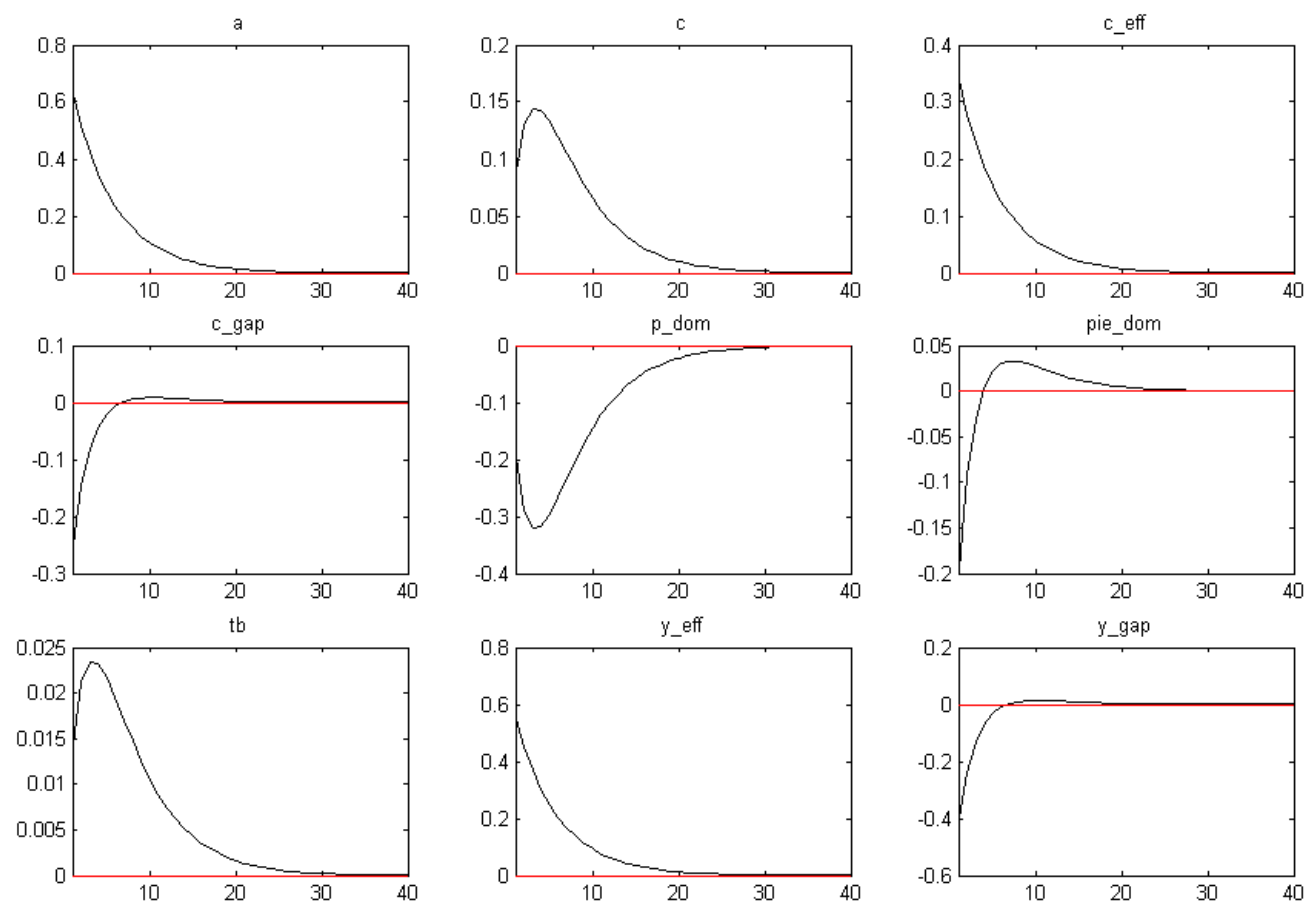

Figure 1: Impulse responses without stabilization policy

Figure 1 shows the impulse responses under a persistent technology shock and without stabilization policy. The positive technology shock (a) increases output and consumption under flexible prices (y_eff and c_eff). The nominal rigidities delay the reaction of actual output and private consumption and cause a negative output and consumption gap (y_gap and c_gap). ${ }^{8}$

\footnotetext{
${ }^{8}$ To determine the consumption gap we first calculate the efficient level of consumption from equation (11) in combination with equation (5). The efficient level is the level of consumption for $\hat{p}_{H, t}^{f}$ and $\hat{\tau}_{t}^{c f}$. We can calculate the flexible-price level by solving (26) for $\hat{p}_{H, t}^{f}$. We then subtract actual from efficient consumption. We
} 
The negative output gap leads to a temporary decline in domestic commodity prices and to temporarily negative inflation rates. The country’s real net exports (tb) slightly increase. ${ }^{9}$ The increase in private consumption increases the country's import demand, but the technology shock also improves the international competitiveness of domestic commodities. Given our model calibration the competitiveness effect prevails and leads to a temporary increase in net exports.

The tables 5 to 8 present the coefficients of the optimal simple instrument rules. The tables 5 and 6 illustrate the optimal contemporaneous reaction to output and price-level volatility. The tables 7 and 8 report the results for fiscal rules with a one-period implementation lag. The tables 5 and 7 contain the optimal coefficients for the inflation-dominated loss function (31a). The tables 6 and 8 give the simple optimal rules for the output-dominated loss function (31b).

\begin{tabular}{|l|c|c|c|c|c|c|c|c|}
\hline & $\phi_{y}$ & $\phi_{\pi}$ & $\phi_{f}$ & $\sigma_{y}$ & $\sigma_{c}$ & $\sigma_{\pi}$ & $\sigma_{\Delta f}$ & Loss \\
\hline No stabilization & - & - & - & 0.50 & 0.31 & 0.24 & - & 0.08 \\
\hline Public spending & -1.41 & -0.59 & 1.23 & 0.24 & 0.40 & 0.14 & 0.33 & 0.06 \\
\hline Consumption tax & 0.17 & 1.10 & 0.97 & 0.40 & 0.56 & 0.21 & 0.30 & 0.07 \\
\hline Income tax & -0.22 & -0.48 & 0.77 & 0.59 & 0.36 & 0.18 & 0.19 & 0.07 \\
\hline
\end{tabular}

Table 5: Optimal simple rule for inflation-dominated loss function ( $\sigma$ indicates standard deviations)

assume that foreign country variables are exogenous, and that fiscal policy variables remain at their steady-state levels if the economy is in its efficient equilibrium. We obtain $\hat{c}_{t}^{f}=\frac{(1-\alpha)(1+\varphi)}{(1-\gamma) \omega_{\alpha} \varphi+\sigma} \hat{a}_{t}$ and $\tilde{c}_{t} \equiv \hat{c}_{t}-\hat{c}_{t}^{f}$.

${ }^{9}$ Real net exports are defined as $X M_{t}=C_{H, t}^{*}-C_{F, t}$. Linearizing the expression via a first-order Taylor expansion and inserting the demand function (4a) as well as the equivalent for foreign household yields $\frac{X M_{t}}{\bar{Y}}=(1-\gamma) \eta\left[(1-\alpha)^{2}-\alpha\right]\left(\hat{p}_{H, t}-\hat{p}_{F, t}\right)+\alpha(1-\gamma)\left(\hat{c}_{t}^{*}-\hat{c}_{t}\right)$. Our simulation assumes that foreign price and consumption levels attain their respective steady state, i.e. $\hat{p}_{F, t}=\hat{c}_{t}^{*}=0$. 


\begin{tabular}{|l|c|c|c|c|c|c|c|c|}
\hline & $\phi_{y}$ & $\phi_{\pi}$ & $\phi_{f}$ & $\sigma_{y}$ & $\sigma_{c}$ & $\sigma_{\pi}$ & $\sigma_{\Delta f}$ & Loss \\
\hline No stabilization & - & - & - & 0.50 & 0.31 & 0.24 & - & 0.25 \\
\hline Public spending & -7.47 & -0.08 & 0.73 & 0.05 & 0.37 & 0.16 & 0.44 & 0.02 \\
\hline Consumption tax & 2.48 & 0.36 & 0.73 & 0.26 & 0.74 & 0.19 & 0.74 & 0.13 \\
\hline Income tax & 0.74 & 0.61 & 0.78 & 0.38 & 0.23 & 0.35 & 0.51 & 0.18 \\
\hline
\end{tabular}

Table 6: Optimal simple rule for output-dominated loss function ( $\sigma$ indicates standard deviations)

Fiscal policy reduces macroeconomic volatility in all four scenarios. In every case the value of the loss function is lower than the loss without stabilization policy. Anti-cyclical government spending is the most efficient stabilization tool, on average. Under the output-dominated loss function, the contemporaneous spending rule achieves a particularly high stabilization gain and brings the output-gap volatility close to zero (see table 6). However, the anti-cyclical spending rule increases the volatility of private consumption around its efficient level. The result is compatible with the findings in Andrés et al. (2003, 2004) and Galí et al. (2004) and due to the composition effect. Public consumption is itself a component of aggregate demand. The anti-cyclical adjustment of government spending hence directly reduces the volatility of output without stabilizing private sector demand. The positive technology shock induces an increase in efficient output and leads to a negative output gap. The optimal expenditure rule reacts through an increase in public consumption, which narrows the output gap. The increase in public expenditure furthermore reduces the marginal costs of production. The coefficients in table 4 illustrate that the deflationary negative wealth effect of increasing government spending is overcompensated by the price-level effect of the increase in output and the reduction of the output gap, however.

The stabilizing potential of the fiscal instruments is more similar in the three other scenarios illustrated in the tables 5,7 and 8 . The optimal coefficients point to a relatively ag- 
gressive reaction of government spending to output gaps and price-level changes. The high coefficient values do not imply particularly strong adjustments of expenditure levels in the process of shock absorption, however. The income tax only affects labor supply and the marginal costs of production in our model of inter-temporal optimization without liquidity constraints. As it only enters the Phillips curve equation it appears particularly well suited for the selective stabilization of commodity prices. The results in the tables 5 and 7 confirm that the income-tax rule is better suited for price-level than for output stabilization. The positive technology shock causes downward pressure on commodity prices. The optimal reaction triggers a temporary increase in income-tax rates. The tax increase reduces the real wage and the labor supply, so that marginal production costs increase. For the output-dominated loss function (31b) the signs of the optimal coefficients change (see tables 6 and 8). The positive technology shock and the negative output gap here induce a reduction of income taxes. The resulting decrease of production costs improves the international competitiveness of domestic commodities. Furthermore, domestic households increase private consumption in response to the price-level decline (see equation 11). Consequently, the demand for domestic production increases and narrows the output gap. Contrary to the two other instruments, the income tax also stabilizes private consumption in tables 6 and 8. Thirdly, the optimal consumption-tax rule implies a reduction of the tax rate in response to the negative values of the output gap and of inflation in the aftermath of the positive technology shock. The temporary tax cut induces optimizing households to increase current relative to future consumption. It leads to an increase in domestic demand and reduces the output gap. Somewhat surprisingly, the optimal consumption-tax rule increases the volatility of private consumption around its efficient level. The increase in volatility follows from equation (11). The rate adjustment induced by the optimal rule leads to an overshooting of consumption relative to the efficient level. The loss reduction under the consumption-tax rule results from its stabilizing impact on the demand for 
domestic commodities. It increases domestic demand and temporarily improves the international competitiveness of domestic production.

\begin{tabular}{|l|c|c|c|c|c|c|c|c|}
\hline & $\phi_{y}$ & $\phi_{\pi}$ & $\phi_{f}$ & $\sigma_{y}$ & $\sigma_{c}$ & $\sigma_{\pi}$ & $\sigma_{\Delta f}$ & Loss \\
\hline No stabilization & - & - & - & 0.50 & 0.31 & 0.24 & - & 0.08 \\
\hline Public spending & -0.30 & -0.56 & 0.90 & 0.46 & 0.36 & 0.18 & 0.24 & 0.06 \\
\hline Consumption tax & 0.03 & 0.82 & 0.93 & 0.47 & 0.42 & 0.22 & 0.20 & 0.07 \\
\hline Income tax & -0.16 & -0.47 & 0.75 & 0.56 & 0.35 & 0.20 & 0.17 & 0.07 \\
\hline
\end{tabular}

Table 7: Optimal simple rule for inflation-dominated loss function and implementation lag

\begin{tabular}{|l|c|c|c|c|c|c|c|c|}
\hline & $\phi_{y}$ & $\phi_{\pi}$ & $\phi_{f}$ & $\sigma_{y}$ & $\sigma_{c}$ & $\sigma_{\pi}$ & $\sigma_{\Delta f}$ & Loss \\
\hline No stabilization & - & - & - & 0.50 & 0.31 & 0.24 & - & 0.25 \\
\hline Public spending & -0.31 & -0.52 & 0.48 & 0.42 & 0.34 & 0.20 & 0.25 & 0.19 \\
\hline Consumption tax & 0.30 & 1.22 & 0.60 & 0.45 & 0.42 & 0.22 & 0.39 & 0.22 \\
\hline Income tax & 0.64 & 0.51 & 0.66 & 0.42 & 0.26 & 0.32 & 0.42 & 0.19 \\
\hline
\end{tabular}

Table 8: Optimal simple rule for output-dominated loss function and implementation lag

Comparing the results for inflation-dominated and output-dominated loss specifications reveals further interesting results. The comparison between the tables 5 and 7, on the one hand, and 6 and 8, on the other hand, shows that the optimal inflation stabilization implies stronger policy persistence, i.e. a bigger $\phi_{f}$, than the optimal rule for output stabilization. The result is compatible with the results in Rotemberg and Woodford (1999) on super-persistent interest rate rules. The optimality of high policy persistence is a consequence of the purely forwardlooking nature of inflation in our model. High policy persistence anchors and stabilizes inflationary expectations, which in turn dampens current inflation. The output equation does not contain a forward-looking component. The optimal degree of persistence is therefore much 
lower for the output-dominated loss specification.

The difference between the forward-looking nature of inflation and the backwardlooking output-gap equation also explains, why the one-period implementation lag does hardly impact on inflation stabilization, but substantially weakens the output-stabilization performance (see tables 7 and 8). The lagged implementation of the tax-rate or expenditure adjustment stabilizes the private sector's inflationary expectations and thus also reduces current price-level fluctuations. As the output equation does not contain a forward component, the lagged implementation has no direct impact on the current output gap. However, the lagged reaction reduces at least future output gaps under the persistent shock.

A third finding in this respect is that the optimal simple rule for lagged output stabilization reacts less to the output gap and relatively stronger to inflation than the optimal contemporaneous rule (see tables 6 and 8). The logic behind this shift from $\phi_{y}$ to $\phi_{\pi}$ is again that the lagged reaction stabilizes current output primarily by its impact on inflationary expectations and the current price level, whereas the contemporaneous rule directly impacts on current demand.

\subsection{The combination of fiscal instruments}

In the previous paragraph, we have considered a single-instrument approach, i.e. the use of only one instrument at one time. We can also combine fiscal instruments, however. Therefore we now investigate whether the combined use of two instrument decisively improves on the stabilization potential of fiscal policy. We simultaneously optimize simple instrument rules for government spending and income taxation and for consumption and income taxes. We

consider the income tax as the complementary instrument because it only has supply-side effects and allows to target labor supply and production costs selectively. We can therefore ex- 
press any possible combination of demand and supply-side effects as a linear combination of public spending or consumption taxes, on the one hand, and the income tax, on the other hand. Table 9 presents the optimal coefficients for the inflation-dominated loss function. Table 10 summarizes the result for a high relative weight on output stabilization.

\begin{tabular}{|c|c|c|c|c|c|c|c|c|}
\hline & $\phi_{y}$ & $\phi_{\pi}$ & $\phi_{f}$ & $\sigma_{y}$ & $\sigma_{c}$ & $\sigma_{\pi}$ & $\sigma_{\Delta f}$ & Loss \\
\hline $\begin{array}{l}\text { Public spending } \\
\text { Income tax }\end{array}$ & $\begin{array}{l}-1.61 \\
0.00\end{array}$ & $\begin{array}{l}-0.19 \\
-2.20\end{array}$ & $\begin{array}{l}0.96 \\
1.00\end{array}$ & 0.22 & 0.59 & 0.00 & $\begin{array}{l}0.36 \\
0.86\end{array}$ & 0.03 \\
\hline $\begin{array}{l}\text { Consumption tax } \\
\text { Income tax }\end{array}$ & $\begin{array}{l}0.81 \\
-0.37\end{array}$ & $\begin{array}{l}-0.44 \\
-0.24\end{array}$ & $\begin{array}{l}0.86 \\
0.83\end{array}$ & 0.47 & 0.65 & 0.14 & $\begin{array}{l}0.31 \\
0.20\end{array}$ & 0.06 \\
\hline
\end{tabular}

Table 9: Simultaneous optimization for inflation-dominated loss function

\begin{tabular}{|l|c|c|c|c|c|c|c|c|}
\hline & $\phi_{y}$ & $\phi_{\pi}$ & $\phi_{f}$ & $\sigma_{y}$ & $\sigma_{c}$ & $\sigma_{\pi}$ & $\sigma_{\Delta f}$ & Loss \\
\hline Public spending & -7.45 & -0.13 & 0.74 & 0.06 & 0.51 & 0.06 & 0.49 & 0.02 \\
\hline Income tax & 0.00 & -0.13 & 1.00 & & & & 0.55 & \\
\hline Consumption tax & 3.07 & -0.65 & 0.73 & 0.25 & 0.55 & 0.26 & 0.64 & \\
\hline
\end{tabular}

Table 10: Simultaneous optimization for output-dominated loss function

Table 9 shows that the combined use of government-spending and income-taxation rules can reduce the inflation-dominated loss by about one half when compared to the single-instrument policy. The income tax only reacts to changes in the price level, whereas the weight of inflation decreases in the spending rule. The combination of both instruments achieves a perfect price level stabilization. Additionally, it slightly reduces output volatility compared to table 6 . The combination of both instruments provides only minor benefits under the outputdominated loss function (see table 10). Output stabilization is comparable to the government- 
spending rule in table 6 . The combined use of consumption and income taxes under the inflation-dominated loss function improves price-level stabilization at the cost of higher output and consumption volatility (see table 9). The simultaneous optimization under the outputdominated loss specification reduces output and consumption gaps, whereas price-level fluctuations increase, however (see table 10). Taken together, the simultaneous optimization of the public-expenditure and the income-tax rule under the inflation-dominated loss function achieves the biggest loss reduction compared to the single-instrument approach. In all other cases, the gains from simultaneous optimization are fairly limited.

\section{Conclusions}

This paper analyses fiscal policy in a micro-founded New Keynesian model of a small open economy inside a monetary union. We model the impact of government expenditure, consumption taxes and income taxes on aggregate demand and supply. Instead of limiting ourselves to the budget surplus as a global indicator of the fiscal stance, we analyze direct taxes, indirect taxes and public spending separately. All these instruments differ in the way they affect the optimum conditions and the behavior of private households and firms. Within the dynamic model we then investigate the potential of fiscal instruments to stabilize macroeconomic fluctuations at the country level. The substitution and wealth effects allow for fiscal stabilization even in our setting of infinitely-lived Ricardian households. As the model context does not imply income effects Under the deficit perspective fiscal policy is commonly assumed to be rather impotent in a Ricardian model without liquidity constraints as it does not imply strong income effects.

The model differs in several aspects from the closed-economy New Keynesian model. 
The common monetary policy, which stabilizes the union aggregate, ensures equilibrium stability and determinacy also in the small member economy. Fiscal policy can nevertheless achieve a substantial reduction of business cycle fluctuations. Concerning the transmission mechanism, the main difference between fiscal and monetary policy in our model is that the former has both direct demand and supply-side effects, whereas the later only affects demand directly. Consequently, fiscal policy enters both the output and the Phillips curve equation.

We then investigate optimal simple rules for fiscal stabilization under a persistent technology shock. We determine optimal rules for an inflation-dominated and for an outputdominated loss function. We also compare the contemporaneous reaction to output and inflation to policy rules featuring an implementation lag. The simple optimal expenditure rule outperforms the consumption-tax and the income-tax rule for both the inflation-dominated and the output-dominated loss function because of its direct demand-driven impact on the output gap. The stabilization gain from anti-cyclical spending is especially pronounced for outputdominated loss specifications. An implementation lag has little impact on the potential of fiscal policy for price-level stabilization, but it deteriorates the performance for output stabilization. Inflation-dominated loss specifications imply a higher instrument persistence than the optimal output-dominated rules. The implementation lag generally leads to less aggressive coefficient values and to a shift in the relative weights of coefficients from the output gap to inflation. The simultaneous optimization of government-spending and income-taxation rules significantly lowers the inflation-dominated loss and achieves a perfect price level stabilization. In all other cases, there are only small benefits from a simultaneous optimization of two instrument rules compared to the optimal single-instrument approach.

Our model assumes inter-temporally optimizing households and firms and an integrated capital market with perfect international risk sharing. The sustainability of public fi- 
nances does not impair business-cycle stabilization if policy affects the private sector primarily via the substitution rather than via its income effects. For simplicity, we furthermore assume that lump-sum transfers are available to balance the government budget.

Considering the case, where the government has to rely on distortionary taxes or expenditure cuts to balance its budget, would be an interesting modification. Another extension consists would be to investigate the stabilizing potential of fiscal policy under deviations from inter-temporal optimization. To this aim, one may model the private sector as an aggregate of inter-temporally optimizing households and Keynesian rule-of-thumb consumers that simply consume the current disposable income (see Mankiw, 2000, Galí et al., 2004). The income effects of taxation and government spending increase in this setting, whereas the substitution effects of fiscal policy decline in importance.

\section{References:}

Andrés, J., R. Doménech and C. Leith (2003), Fiscal Policy, Macroeconomic Stability and Finite Horizons, mimeo.

Andrés, J., R. Doménech and A. Fatás (2004), The Stabilizing Role of Government Size, mimeo.

Beetsma, R. and H. Jensen (2002), 'Monetary and fiscal policy interactions in a microfounded model of a monetary union’, ECB Working Paper 166.

Beetsma, R. and H. Jensen (2004), 'Mark-up Fluctuations and Fiscal Policy Stabilization in a Monetary Union', Journal of Macroeconomics 66, 357-376. 
Benigno, P. and M. Woodford (2003), Optimal Monetary and Fiscal Policy: A LinearQuadratic Approach, NBER Working Paper 9905.

Blanchard, O. and Ch. Kahn (1980), 'The Solution of Linear Difference Models under Rational Expectations', Econometrica 48, 1305-1311.

Blinder, A. (2004), 'The Case Against the Case Against Discretionary Fiscal Policy’, CEPS Working Paper 100.

Calvo, G. (1983), 'Staggered Prices in a Utility-Maximizing Framework', Journal of Monetary Economics 12, 383-398.

Clarida, R., J. Galí and M. Gertler (1998), 'Monetary Policy Rules in Practice: Some International Evidence’, European Economic Review 42(6), 1033-1067.

Clarida, R., J. Galí and M. Gertler (1999), ‘The Science of Monetary Policy: A New Keynesian Perspective', Journal of Economic Literature 37, 1661-1707.

Dennis, R. (2003), The Policy Preferences of the US Federal Reserve, mimeo.

Dieppe, A., K. Küster and P McAdam (2005), 'Optimal Monetary Policy Rules for the Euro Area: An Analysis Using the Area Wide Model', Journal of Common Market Studies 43(3), 507-537.

European Commission (2003), European Economy: Statistical Annex, Office for Official Publications of the EC, Luxemburg.

Favero, C. and R. Rovelli (2001), Macroeconomic stability and the preferences of the Fed: A formal analysis 1961-98, IGIER Working Paper 200.

Galí, J. and T. Monacelli (2002), 'Monetary policy and exchange rate volatility in a small 
open economy’, NBER Working Paper 8905.

Galí, J. and T. Monacelli (2005), ‘Optimal Monetary and Fiscal Policy in a Currency Union’, NBER Working Paper 11815.

Galí, J., M. Gertler and D. Lopez-Salido (2001), ‘European inflation dynamics’, European Economic Review 45, 1237-1270.

Galí, J., D. Lopez-Salido and J. Vallés (2004), Understanding the Effects of Government Spending on Consumption, ECB Working Paper 339.

Gerberding, Ch., A. Worms and F. Seitz (2004), How the Bundesbank really conducted monetary policy: An analysis based on real-time data, Deutsche Bundesbank Discussion Paper 25/ 2004.

Gerdesmeier, D. and B. Roffia (2004), 'Empirical Estimates of Reaction Functions for the Euro Area', Swiss Journal of Economics and Statistics 140(1), 37-66.

Herz, B., W. Roeger and L. Vogel (2004), Fiscal Stabilization in a Small Open Economy, University of Bayreuth Discussion Papers in Economics 10-04.

Juillard, M. (1996), 'Dynare: A program for the resolution and simulation of dynamic models with forward variables through the use of a relaxation algorithm', CEPREMAP Couverture Orange 9602.

Levine, A., V. Wieland and J. Williams (1999), 'Robustness of Simple Monetary Policy Rules under Model Uncertainty’, in: J. Taylor (ed.), Monetary Policy Rules, University of Chicago Press, Chicago, 263-318.

Mankiw, G. (2000), ‘The Savers-Spenders Theory of Fiscal Policy’, American Economic Re- 
view 90, 120-125.

Mayer, E. (2003), The Mechanics of a Reasonably Fitted Quarterly New Keynesian Macro Model, Wuerzburg Economic Papers 41.

Muscatelli, A., P. Tirelli and C. Trecroci (2004), Can Fiscal Policy Help Macroeconomic Stabilization? Evidence from a New Keynesian Model with Liquidity Constraints, CESifo Working Paper 1171.

Muscatelli, A., P. Tirelli and C. Trecroci (2004a), 'Fiscal and monetary policy interactions: Empirical evidence and optimal policy using a structural New-Keynesian model', Journal of Macroeconomics 26, 257-280.

OECD (2004), OECD Tax Database, OECD, Paris.

Rotemberg, J. and M. Woodford (1999), 'Interest rate Rules in an Estimated Sticky Price Model', in: J. Taylor (ed.), Monetary Policy Rules, Chicago University Press, Chicago, 57-126.

Taylor, J. (1993), 'Discretion versus policy rules in practice’, Carnegie-Rochester Conference Series on Public Policy 39, 195-214.

Sargent, Th. (1987), Macroeconomic Theory, Academic Press, Boston.

Smets, F. and R. Wouters (2003): ‘An Estimated Dynamic Stochastic General Equilibrium Model of the Euro Area', Journal of the European Economic Association 1, 1123-1175.

Söderström, U., P Söderlind and A. Vredin (2002), Can a Calibrated New-Keynesian Model of Monetary Policy Fit the Facts?, Sveriges Riksbank Working Paper Series 140.

Taylor, J. (1998), Staggered Price and Wage Setting in Macroeconomics, NBER Working 
Paper 6754.

Taylor, J. (1999), 'Introduction’, in: J. Taylor (ed.), Monetary Policy Rules, Chicago University Press, Chicago, 1-14.

Van Aarle, B., H. Garretsen and F. Huart (2004): 'Monetary and Fiscal Policy Rules in the EMU’, German Economic Review 5, 407-434.

Woodford, M. (2003), Interest and Prices, Princeton University Press, Princeton. 